\title{
Case Study of Online Banking in India: User Behaviors and Design Guidelines
}

\author{
Jhumkee Iyengar $^{1}$ and Manisha Belvalkar ${ }^{2}$ \\ ${ }^{1}$ User in Design, Principal Consultant, 102, Gartner House, Nachiket Park, Baner Road, \\ Pune 411045, India \\ ${ }^{2}$ Pure IT Usability Research, Practice Head, Tanntrr, 1187-11, Vasantrao Deshmukh Road, \\ Shivajinagar, Pune, 411005, India \\ jhumkee@userindesign.com, manisha@pureuse.com
}

\begin{abstract}
This paper documents online banking trends, behaviors and expectations of Indian consumers and banks. It is based on excerpts of a large industry case study of users from 4 leading banks. While banks view online banking essentially as a technology solution, it is a relatively new area for Indian consumers and not yet self-supporting. Being a savings based culture still, Indian consumers are cautious about their financial assets. They are also relatively recent entrants to internet based services. Design of these systems must therefore be based on an understanding of these users' outlook and priorities through task centric, security assured and service oriented solutions minus the technological challenges. Design lessons suggest viewing online banking not just as a convenience alone anymore but beyond it, to provide service, simplicity and security. This will create satisfied online banking customers and therefore profitability for the bank.
\end{abstract}

Keywords: Banking, online banking, user perception of banking, banking in India.

\section{Introduction}

The Internet has revolutionized the way we live, shop, entertain and interact and also the way we save and invest. Internet banking arrived in India in the late 1990s [1]. ICICI was the first bank to champion its usage and introduced internet banking to its customers in 1996. With lower internet costs and increased awareness about electronic media, online banking established itself only in 1999. Other banks followed suit, including HDFC, Citibank, IndusInd and the now redundant Times Bank [2].

Internet banking changed both the banking industry as well as banks' services to its customers. 'Anywhere banking' came to be recognized as an opportunity also for differentiated and competitive services. Ancillary online services like checking account status, fund transfer, ordering demand drafts, loan applications, credit card verifications, shopping portals etc. as well as not requiring a visit to the branch during office hours were viewed as high-value offerings and increasingly started to become a necessity rather than a service. 
Once banking institutions recognized the low processing cost per transaction via the internet, they began viewing online banking as an extension of the bank rather than as an add-on service. The motivation to introduce online banking now also included new business potential, additional funds from new and existing customers, expansion in geographical reach, image as a tech-savvy bank especially if targeting the youth and the threat of customers shifting loyalty if they did not introduce it [3].

Nationalized banks initially viewed online banking as insecure and counterintuitive and were therefore hesitant. But eventually, SBI, Canara Bank, Allahabad Bank, Punjab National Bank, Bank of Baroda, Syndicate Bank and others introduced it. SBI launched internet banking in 2001 and experienced good response. In general, internet banking saw an exponential rise in users [4].

Today, banks encourage their customers to use online banking. Besides cost and revenue impacts, this paradigm shift is because they also recognize that self-control transactions have greater potential for customer satisfaction and retention. Online banking has thus come to be among essential banking services.

The approach to adopting online banking however is often to merely stay abreast of industry and technology and online banking is becoming a separate business unit driven by technological possibilities. The user often has minimal place in such an approach as evidenced by non-human centric experiences that flourish. However, the cultural and organizational shift needed by Indian banks to draw old customers into this new banking channel as well as to draw new customers requires a user centric focus.

But how much have banks paid attention to the user? How is the overall experience and how do customers perceive their bank as they struggle unaided in the comfort of their homes? How cognizant are banks that customers silently leave after getting frustrated? Do they measure how much revenue they are losing because of a technology focused approach to online banking? How do Indian consumers behave in this dichotomy between technology barrier and convenience?

\section{Indian Banking Industry and Online Awareness of Its User Base}

A large chunk of the Indian banking industry still belongs to the public sector banks having the most extensive network of physical branches. These are followed by large private banks and lastly by multinational banks (MNC) who have the smallest physical network and therefore their online banking needs to be the most developed and able to address user needs without requiring human intervention. This is depicted in Figure 1. The fact that most government organisations have their payroll accounts with public sector banks contributes significantly to the large customer bases of these banks. Traditional public sector banks have existed for many years and have serviced diverse income groups. This has resulted in their customer base being huge as well as belonging to a wider demographic representation, given India's heterogenous population as well. However, most of the traditional customers prefer to bank with a 'bank with a human touch' and prefer public sector banks as they form an emotional relationship with their bank personnel, which is not really encouraged by private sector or multi-national banks [5]. 


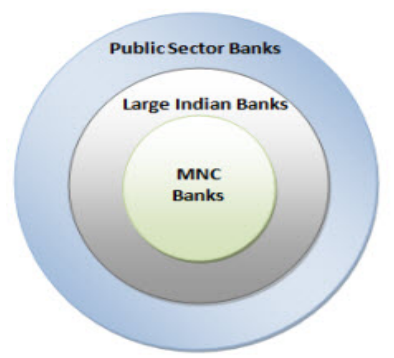

Fig. 1. Indian Banking Scenario (representative only, not to scale)

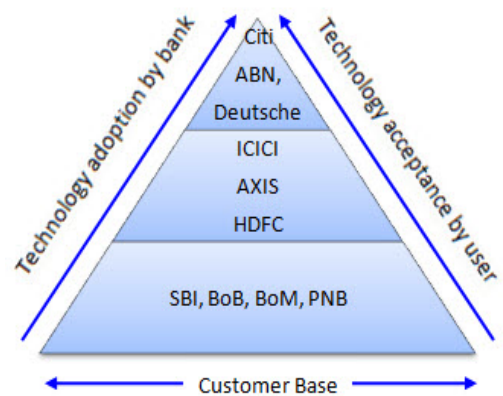

Fig. 2. Indian Internet Banking Landscape (representative only, not to scale

The new generation which has been banking for less than a decade prefers faster transactions and more professional relationships as compared to the traditional customer. For them, opening a bank account is incidental and connected to their direct deposit salary accounts. The private sector bank has captured the corporates and IT sector as compared to the public sector bank. As a result, banks in the public sector tend to have a huge user base, but very few of their customers have the technology orientation or the inclination to use electronic media for banking. This is depicted in Figure 2. Therefore, the awareness of customers of public sector banks about online banking as an active banking tool is relatively lower. To tap this type of user base that has an inherent barrier to and not an obvious need for internet usage, just adding an internet banking channel to a bank's lists of services may not be enough of an incentive. A streamlined, simple and customer satisfaction oriented approach to service novice users only can help banks achieve better internet banking penetration.

\section{User Research Study}

\subsection{Objectives}

User research studies of four banks were conducted to understand users' current relations with their bank, their perception of offline and online banking services and to offer recommendations for more customer-focused services. We specifically investigated:

- Users' offline and online expectations of their bank and association with its brand

- Homepage as a touch point for encouraging online banking

- Customer engagement barriers for online banking services

- Concept of new online services like branchless banking.

\subsection{Methodology}

The methodology involved recruiting and studying users from the banks' customer database, categorized on the basis of usage and transactional behaviours. The 3 types of users interviewed were: 
- Non-users who don't bank online

- Users who bank online but only check account status and don't do any transactions

- Users who perform extensive online transaction via their bank account

Table 1. Classification of studies conducted and methodology applied

\begin{tabular}{lllcl}
\hline No. & Objective of Study & $\begin{array}{l}\text { Method and } \\
\text { Techniques }\end{array}$ & $\begin{array}{l}\text { No of } \\
\text { Users }\end{array}$ & Cities \\
\hline 1. & $\begin{array}{l}\text { Offline and online } \\
\text { expectations and association } \\
\text { with the brand }\end{array}$ & Quantitative research & 800 & $\begin{array}{l}\text { Mumbai, } \\
\text { Ahmedabad, } \\
\text { Delhi, Jaipur }\end{array}$ \\
2. & $\begin{array}{l}\text { Homepage as touch point } \\
\text { for encouraging online } \\
\text { banking }\end{array}$ & $\begin{array}{l}\text { Usability Test and } \\
\text { One-on-one Interview }\end{array}$ & 48 & Mumbai, Pune \\
3. & $\begin{array}{l}\text { Identify customer } \\
\text { engagement barriers in } \\
\text { online banking }\end{array}$ & $\begin{array}{l}\text { Usability Test and } \\
\text { One-on-one Interview }\end{array}$ & 48 & Mumbai, Pune \\
Concept Testing for new & Focus Group & 48 & Bangalore, \\
online services & Discussion & & Mumbai, Delhi \\
\hline
\end{tabular}

\section{Findings: User Perceptions and Attitudes to Online Banking}

In response to how they perceived their general banking experience, users mentioned requirements mentioned below that have been detailed in Table 2:

- zero minimum balance

- $\quad$ presence of ATM 'everywhere' (redundant now as all ATMs are connected)

Table 2. User perceptions and expectations

\begin{tabular}{lcccc}
\hline Users' Perception & \multicolumn{3}{c}{ Priority } & Total \\
& $\mathbf{1}$ & $\mathbf{2}$ & $\mathbf{3}$ & \\
\hline Zero minimum balance & 410 & 135 & 95 & $\mathbf{6 4 0}$ \\
$\begin{array}{l}\text { Presence of bank's ATM } \\
\text { "everywhere }\end{array}$ & 372 & 150 & 58 & $\mathbf{5 8 0}$ \\
$\begin{array}{l}\text { Proximity from home/work } \\
\begin{array}{l}\text { Fast growing and high savings } \\
\text { interest rates }\end{array}\end{array}$ & 220 & 115 & 105 & $\mathbf{4 4 0}$ \\
$\begin{array}{l}\text { Air-conditioned interiors } \\
\text { Responsive banking }\end{array}$ & 40 & 80 & 228 & $\mathbf{3 6 0}$ \\
& 15 & 160 & 125 & $\mathbf{3 0 0}$ \\
\hline
\end{tabular}

Base -800 respondents (Multiple responses). 
- $\quad$ proximity from home/work

- fast growing and high savings interest rates

- air-conditioned interiors

- $\quad$ responsive banking

It was seen that the ability to bank without visiting the branch was a high priority.

Responses to queries about their online banking experience, expectations and concerns by user segments have been generalized and detailed in Table 3 below.

Table 3. Issues of different types of users with online banking

\begin{tabular}{lll}
\hline Non-users & Non-transactors & Transactors \\
\hline $\begin{array}{l}\text { Inhibited about security of } \\
\text { sensitive information }\end{array}$ & Felt lost in content jungle & $\begin{array}{l}\text { Looked for error-free } \\
\text { transaction experience }\end{array}$ \\
$\begin{array}{l}\text { Found the entire process } \\
\text { complex }\end{array}$ & $\begin{array}{l}\text { Concerned about online } \\
\text { security }\end{array}$ & $\begin{array}{l}\text { Valued advanced options } \\
\text { that saved time }\end{array}$ \\
$\begin{array}{l}\text { Absence of an online demo for } \\
\text { initiation is a roadblock }\end{array}$ & $\begin{array}{l}\text { Did not find clear directions } \\
\& \text { action points }\end{array}$ & $\begin{array}{l}\text { Wanted online, the entire } \\
\text { spectrum of services of the } \\
\text { bank }\end{array}$ \\
\hline
\end{tabular}

Broadly, all users emphasized 3 major attributes they considered important for their online banking experience: Simplicity, Security, Service.

\subsection{Simplicity}

Users and non-users expect online banking to be further simplified than what they see today. Some expectations:

- Better link label clarity suggestive of action required

- Better navigation that highlights and presents relevant information in context and at the right time needed

- Better content partitioning according to popularity and priority of action.

\subsection{Security}

Non-transactors and non-users reported that they did not transact online because:

- concerns about the security of their banking information is not fully addressed

- technical glitches and unreliability create confusion and anxiety

- $\quad$ additional security gateways were absent.

\subsection{Service}

Almost all transactors demanded better service. They wanted:

- More services to be available online

- Better and faster customer support channels like online chat to solve banking hurdles

- Innovative and intuitive interface. 
This is depicted in Figure 3 below.

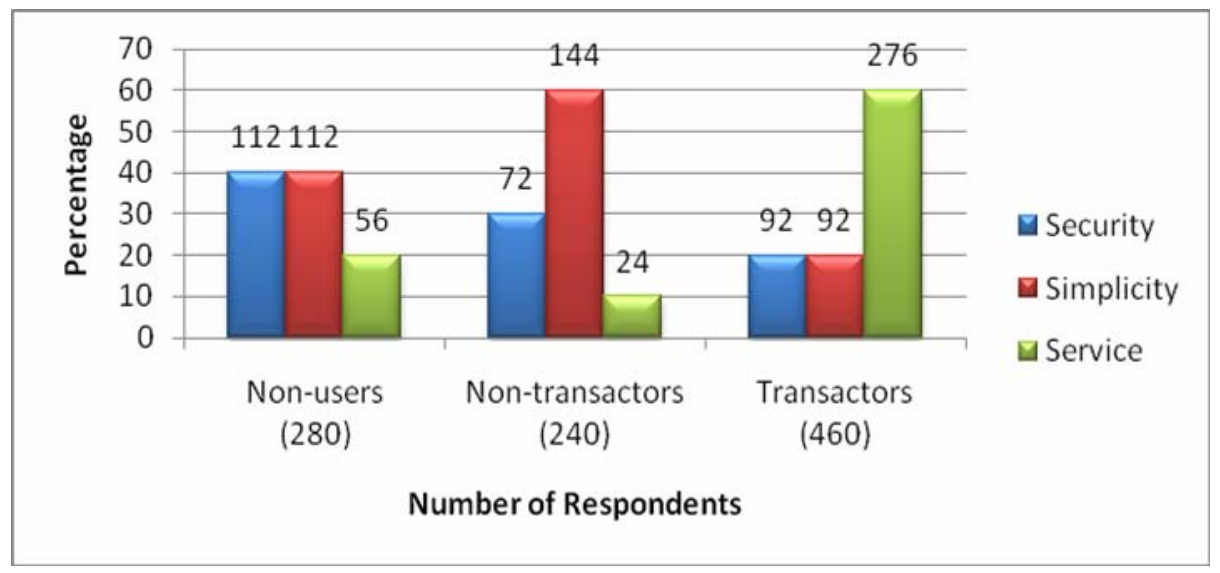

Fig. 3. Users' emphasis on attributes according to their usage

\section{Banking Industry Perspective and Approach to Users}

Based on our client interactions before and after the studies, we found that banks view online banking as an important medium of servicing its customer base. While they recognize it as a direct cost savings, they do not necessarily recognize it as a point of service and hence do not give it the attention they give customer service at the branch where they take great pains to satisfy the customer, and to address the smallest of queries common in live banking.

A simple example is their changing banking terminology without realizing its impact on the customer that can leave an average customer baffled. A label like 'Emonies National Funds Transfer' is very confusing for the customer. Changing it to a simpler 'Funds Transfer' reduces confusion and allows the customer to complete their transaction. Another example is use of marketing gimmicks resulting in loss of usability. If other banking portals have a link called 'SMS Alert', then coining a similar link called 'InstaAlert' only serves to create confusion.

Many banks have now understood that online banking is here to stay and that they need to upgrade and enhance their offerings for simple solutions and desired security to retain and attract customers [6]. They also need to recognize that they must offer the same convenience and service that people have come to expect at the branch as well as in other areas of their life like shopping online [1]. Payment for shopping too requires users to invariably go through the online banking portals. Banks need to also understand that transition of a new user to an advanced one is a gradual process that needs to be supported by encouraging users to explore with confidence by offering intuitive processes and user-friendly nomenclature. Only when users feel confident with the system, will it be easy for them to explore new services through cross-sell banners and other means that are popular and successful in banking. 
Banks are however yet to regard online banking as a 'person-less' service counter where the user is left to fend for himself/herself amidst stiff usability barriers and realize that it costs them. The attention they accord their other points of service are therefore deficient in online. (See Fig. 4) Setting up the hardware for online banking, which is viewed as the end point for the bank is often the beginning from a user's perspective. That a methodical user-centric rather than a technology-centric design approach is a systemic investment that creates satisfied customers, reduces costs and increases revenue is yet to be accepted by the banking industry.

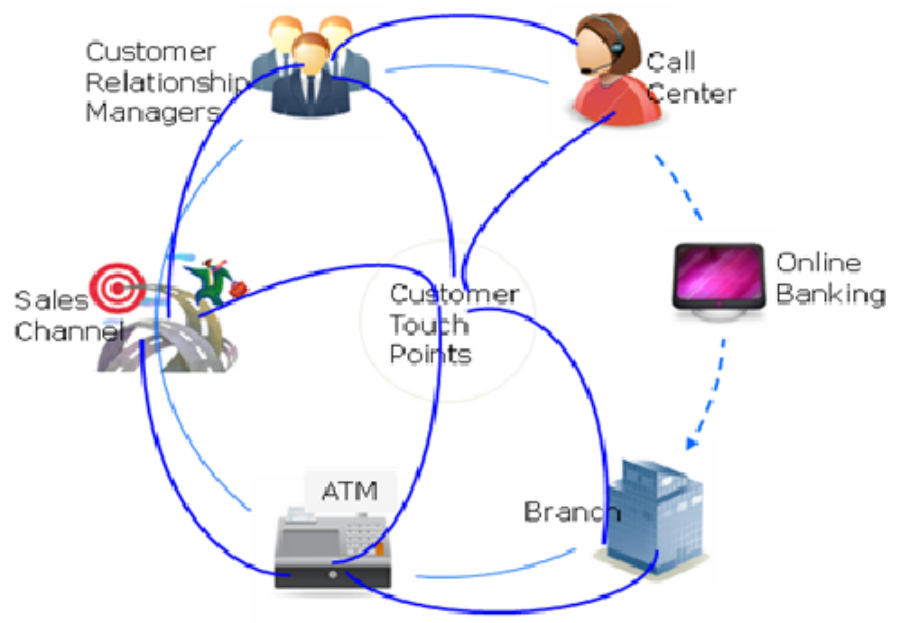

Fig. 4. Services offered via various banking channels

\section{Design Lessons and Recommendations}

Banking is a task-focused activity and also deals with people's money. Both need ease of use and psychological comfort of the user as fundamental requirements, for example, giving feedback like 'your money will be transferred in 24 hours'. It specifically needs a clear task flow, clarity of language and terminology and support available at all times. Further, if a task completion process is intuitive and logical, the user is more likely to gain confidence and increase usage of the internet for all their banking needs, thus increasing revenue potential for the bank. An online demo of the service is an easy way to address both the task centric nature of banking as well as address the comfort level of the wide variety and vast numbers of novice users.

An example of customer focused online banking would be specialized banking for the Islamic community. It is a huge business opportunity. To capitalize on that opportunity, banks must understand and design for highly specialized user behavior, expectations and critical aspects of the various Islamic cultures. Many Islamic cultures are exceptionally collective in decision-making and tend to be more concrete and riskaverse [7].

There is a wide variety and large numbers of novice users among Indian online banking customers today. Their view goes beyond the novelty of online banking. 
They expect their experience to be similar to what they get at a service counter. The unfamiliar virtual experience cannot be completely different from their familiar physical experience. Indian users have shown their readiness to accept online banking as a sales channel by purchasing through cross selling online. But this is possible only if they are able to navigate the bank site. Banks need to view and reflect this through thoughtful designs of their offerings. While banks have clarity of their market segmentation, they must progress to behavior-based segmentation and user-centred methods and move beyond predesigned technology solutions. Online banking design must create a 'quick in and out' experience, ensure success in transactions users undertake, arouse curiosity and attract the customer to explore. Studying users, defining user types, benchmarking designs and testing for ease of use are critical for this. Specific needs therefore are: clear task flows, brevity and clarity of language and terms, basic functions made obvious to average users and support available at all times. Besides short-term solutions, the long-term strategy needed is to not just create but also measure user performance with the design to ensure it is self-evident and transactions are truly self-controlled.

\section{Conclusions}

It is clearly in the interest of banks to encourage their customer base to use online banking. Current designs of online banking systems do not address users' needs and expectations of online banking. User-centred design methods can achieve this. Internet, phone, paper statements, ATM and visit to the branch all need to appear as one holistic experience [8] for the customer who is 'anybody. In India, banking, like several other transactions, continues to be relation-based and in need of human assurance and intervention, technology notwithstanding. Hence this is particularly significant. True benefits will be seen when banks use this technology to offload customer service costs and increase sales by maximizing self-service. As $21^{\text {st }}$ century banking users entrust the care of one of their most important assets to cyber space, a seamless, stress free and successful experience is essential. Design with users' success as focus, content understandable by 'anybody', supported with demos and help to reduce intimidation, will justify investment in online through increased usage by satisfied customers.

\section{References}

1. Srivastava, Dr.: Saurabh Internet Banking - A Global Way to Bank!, http: / / www. indianmba.com/Faculty_Column/FC908/fC908.html

2. De, Rajneesh and Padmanabhan, Chitra for Indian Express Group, Internet opens new vistas for Indian banks,

http: / / www . expresscomputeronline.com/20020916/indtrend1. shtml

3. Singh, R.P.: Whither Internet Banking in BankNetIndia, http: / / www . banknetindia.com/banking/rps.htm

4. The Indian internet Banking Journey, http: / /www. icmrindia.org/free\%20resources/casestudies / banking1.htm 
5. Singh, Karan, M.: Public sector banks score over private ones, http: / /www. downtoearth.org.in/

Ful16.asp? FolderName=20061231\&FileNAme=news\&sid=3\&sec_id=4

6. Kekre, Priya: Phishing in India on the rise, http: / /www.ciol.com/Enterprise/BFSI/Feature/ Phishing-in-India-on-the-rise/301008112099/0/

7. Shaffer, E.: The Evolving Institutionalization of Usability, a White Paper, http: / / www. humanfactors. com

8. Merholz, P., Wilkens, T., Schauer, B., Verba, D.: Subject To Change: Creating Great Products \& Services for an Uncertain World

9. Norman, D.: Emotional Design: Why We Love (or Hate) Everyday Things 